\title{
What's New in Endocrinology: The Chromaffin Cell
}

\author{
Lee E. Eiden* and Sunny Zhihong Jiang
}

Section on Molecular Neuroscience, Laboratory of Cellular and Molecular Regulation, Intramural Research Program, National Institute of Mental Health, Bethesda, MD, United States

Recent advances in understanding the intracellular and intercellular features of adrenal chromatin cells as stress transducers are reviewed here, along with their implications for endocrine function in other tissues and organs participating in endocrine regulation in the mammalian organism.

Keywords: chromaffin cell, catestatin, PACAP, interleukin 6, gap junction, NCS-Rapgef2

\section{OPEN ACCESS}

Edited by:

Derek LeRoith

Icahn School of Medicine at Mount

Sinai, United States

Reviewed by:

Illana Gozes,

Tel Aviv University, Israel

Youssef Anouar,

Institut National de la Santé et de la

Recherche Médicale (INSERM),

France

${ }^{*}$ Correspondence:

Lee E. Eiden

eiden/@mail.nih.gov

Specialty section:

This article was submitted to Neuroendocrine Science,

a section of the journal

Frontiers in Endocrinology

Received: 17 August 2018 Accepted: 12 November 2018 Published: 04 December 2018

Citation:

Eiden LE and Jiang SZ (2018) What's New in Endocrinology: The Chromaffin

Cell. Front. Endocrinol. 9:711.

doi: 10.3389/fendo.2018.00711

\section{INTRODUCTION}

It is sometimes useful to view the sprawling field of endocrinology through a narrow window to view advances that might otherwise be lost in the larger and more chaotic picture. Here, we take the opportunity to review briefly recent advances in our understanding of the regulation of the mammalian adrenal medulla, the storehouse for secretion of epinephrine that is critical for cardiovascular, neuronal, and metabolic homeostatic control, especially during stress. We compare the accepted view of the adrenal medulla of the twentieth century, still promulgated in most textbooks, and what we know about its function given recent information over the past decade or so. In each of five areas, we present "foundational" data, and then review emerging information sets that have significantly changed how the adrenal medulla is viewed as a stress-transducing endocrine tissue, and in addition shed significant light on the function of other mammalian endocrine organs and systems.

The first area in which significantly new developments in our understanding of chromaffin cell function have occurred is the emergence of the neuropeptide PACAP, rather than acetylcholine, as the physiologically dominant splanchnicoadrenomedullary synaptic neurotransmitter during stress. A second is the discovery in adrenal medulla of a neuroendocrine-specific cyclic AMP effector that propagates signaling for gene regulation in response to stress into the chromaffin cell. Third, peptides found in adrenal medulla and released from it may have important paracrine and autocrine roles, while their roles as both biomarkers and physiological actors is still unfolding. A fourth emerging concept is that chromaffin cells of the adrenal medulla work together via altered gap junction coupling and cellular adhesion during certain physiological states, predominantly in stress. Finally, we are becoming aware, with acquisition of new in vivo and cell culture data, that the adrenal medulla is not only the original "stress transducer" of the body, but also a regulatory nexus for the secretion of peptides important in stress-inflammation interactions and in integration of stress responding with the sensory nervous system. We will take each of these points in order, and end by summarizing how an updated view of adrenomedullary function has illuminated endocrine cell and organ function in general (Figure 1). 


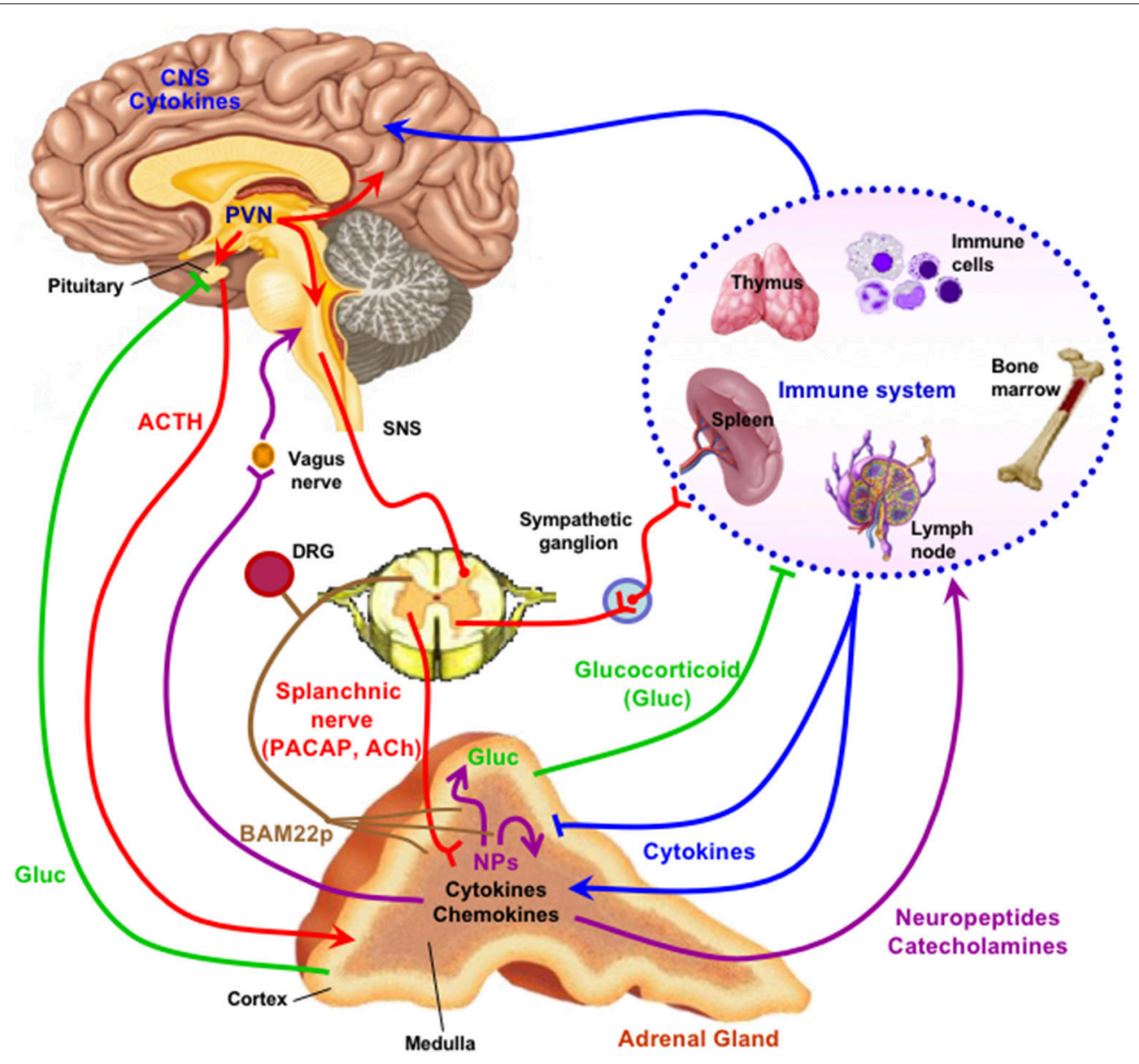

FIGURE 1 | The adrenal medulla as a stress transducer and neuroimmunoinflammatory and cardiovascular regulator. Cytokines are delivered to receptors on chromaffin cells as blood-borne messengers or via mobile secreting cells such as monocytes/macrophages; neurotransmitters PACAP and ACh are delivered to receptors on chromaffin cells via the splanchnic nerve. Activation of chromaffin cell signaling pathways (see Figure 2) increase expression of genes encoding neuropeptides (NPs), other mediators, catecholamine biosynthetic enzymes, and adhesion factors and connexins that increase cell-cell communication among chromaffin cells, and amplify catecholamine, neuropeptide, and chromogranin output in response to stress. Secreted neuropeptides such as galanin may in turn act upon the adrenal cortex to modulate glucocorticoid output; catecholamines act as hormones at cardiovascular and other targets; chromogranins and their derived peptides have both autocrine and paracrine actions in the adrenal medulla and also as hormones; BAM-22P may act on receptors on sensory neurons innervating the adrenal gland. For further explication of the figure, see the text. Note that there is some degree of species specificity to expression of cytokines and neuropeptides in adrenal medulla, so that the schematic offered here may differ in some particulars depending on the species, including $H$. sapiens, under consideration (1-8). Figure adapted from (9).

\section{PACAP AS A STRESS TRANSMITTER AT THE SPLANCHNICOADRENOMEDULLARY SYNAPSE}

Almost 70 years ago, Rex Coupland properly defined the first peripheral synapse, through electron microscopical observation, detailing the innervation of chromaffin cells of the golden hamster adrenal medulla by the cholinergic sympathetic pre-ganglionic fibers of the splanchnic nerve (10). Somewhat earlier, the storage of epinephrine (and norepinephrine) within secretory granules was characterized (11). The morphological, cell biological, and biochemical aspects of chromaffin cell function were integrated by several additional observations. These included the ultrastructural observation of the epinephrine-containing secretory granules presenting an omega-shaped profile to the extracellular space of the chromaffin cell by Coupland; the determination that a large protein (chromogranin A) was contained in and secreted from the adrenal medulla upon splanchnic nerve stimulation [see for original pertinent literature $(12,13)]^{1}$; and finally the observation that cholinergic and nerve stimulation was calcium-dependent (14). A rich cascade of concepts followed, and culminated in Douglas's idea of stimulus-secretion coupling

\footnotetext{
${ }^{1}$ As often as possible, in the interests of brevity, review articles in which the historical documentation of discovery can be perused, will be cited in lieu of the primary literature.
} 
(15), in analogy to muscle stimulus-contraction coupling. In this case, a transmitter released from the splanchnic nerve excited the chromaffin cell through an ionotropic receptor, calcium influx occurred, and exocytosis followed, with the release of granular proteins and catecholamines into the circulation. The transmitter released from the splanchnic nerve (and at all other preganglionic sympathetic/sympathoadrenal synapses) of course was acetylcholine. It caused cellular depolarization through the nicotinic cholinergic receptor, and exocytotic secretion ensued (16). Subsequently, the splanchnicoadrenomedullary synapse became the paradigm for peripheral neurotransmission at sympathetic as well as parasympathetic ganglia.

The ability of acetylcholine to generate an action potential by acting upon sodium channels on chromaffin cells (and post-ganglionic sympathetic and parasympathetic neurons) explained its secretagogue activity for epinephrine release from the adrenal medulla (16). Similar nicotinic receptor activation on post-ganglionic sympathetic and parasympathetic neurons was responsible for norepinephrine and acetylcholine release (respectively) at autonomic neuroeffector junctions in heart, spleen, lymphatic tissue, and elsewhere throughout the body. The possibility for additional complexity, however, in the neurotransmitter coding of the autonomic nervous system began to arise in the late 70 s with several laboratories exploring the long-term changes in chromaffin cells driven by stress-induced catecholamine secretion. Wakade and colleagues discovered that the adrenal medulla may release its entire complement of catecholamines during a bout of secretion lasting several hours, yet remain competent for secretion afterwards due to heroic repletion of the gland: at the end of a secretory bout that releases all of the epinephrine present in the adrenal medulla at the start of secretion, there remains as much epinephrine as before (17). The gland re-synthesizes its entire store of accumulated epinephrine in a few hours. How does this occur? Costa and colleagues explored the induction of the rate-limiting enzyme for catecholamine biosynthesis, tyrosine hydroxylase (TH), and determined that through both transcriptional and post-translation activation mechanisms, long-term splanchnicoadrenomedullary stimulation would induce $\mathrm{TH}$ and this would in turn increase the rate of catecholamine biosynthesis in a compensatory way (18). Possible mechanisms for this (since nicotinic stimulation was limited in its ability to induce $\mathrm{TH}$ as well as peptide synthesis in the gland) included the activation of muscarinic cholinergic receptors (19). Thoenen et al., however, noted that reflex stimulation of chromaffin cells in situ by whole-animal treatment with reserpine caused an induction of $\mathrm{TH}$ that could not be blocked with nicotinic or muscarinic blockers, and opined that either a novel type of cholinergic receptor must exist or, presciently, that a non-cholinergic substance might be released along with acetylcholine to allow TH induction (20). Ip and Zigmond posited something similar at sympathetic ganglion, where stimulation of the sympathetic trunk at $10 \mathrm{~Hz}$ (frequency typical of the stress response) caused in the superior cervical ganglion the induction of $\mathrm{TH}$ by a mechanism that could be pharmacologically explained only partially through an action of acetylcholine release from preganglionic terminals (21). The situation languished until the discovery of the neuropeptide pituitary adenylate cyclase-activating polypeptide (PACAP) (22) by Miyata et al. Despite its name, and its discovery as a hypothalamic peptide able to stimulate cAMP production in perfused anterior pituitary hemi-organs (23), three remarkable properties of PACAP were soon discovered. First, it was ubiquitously expressed in brain, and not only hypothalamus; second, it was present in peripheral tissues; third, application of PACAP in various contexts potently stimulated epinephrine secretion from the adrenal gland in vivo, from perfused adrenal gland ex vivo, and from chromaffin cells in culture [(24-27) and references therein].

The development of PACAP-deficient mice allowed characterization of antibodies that were unambiguous in detecting PACAP (compared to its structurally similar congener VIP) in the cholinergic nerve terminals of the splanchnic nerve within the adrenal gland (28). The PACAP knock-out mouse also allowed examination of the role of PACAP on adrenomedullary performance in vivo. Reflex stimulation of the splanchnic nerve after hypoglycemia induced by insulin shock increased plasma epinephrine levels, and adrenomedullary TH activity: both effects were blunted or abolished in PACAP-deficient mice, and correction of hypoglycemia did not occur, a fatal outcome unless prevented by intraperitoneal injection of PACAP or glucose itself (28). Later experiments conducted in adrenal slices ex vivo showed that epinephrine secretion upon splanchnic nerve stimulation at high frequency, but not at low stimulation rates, does not occur in slices from PACAP-deficient mice or from wild-type mice when perfused with the PACAP antagonist PACAP(6-38) $(29,30)$.

What have we learned? First, PACAP is present at each of the splanchnic nerve terminals that contain cholinergic secretory vesicles and innervate the mouse adrenal chromaffin cells. Second, stress-induced catecholamine secretion and biosynthetic enzyme regulation is PACAP-dependent, regardless of whether the stressor is metabolic/systemic (e.g., insulininduced hypoglycemia) or exteroceptive/psychogenic (e.g., restraint stress). Second, this dependence can be shown to exist at the level of the adrenal gland itself, since adrenal slices taken from PACAP-deficient mice, in which the morphology and neurochemistry of the splanchnicoadrenomedullary synapse is normal, fail to release epinephrine in response to high-frequency stimulation of the splanchnic nerve stump, while basal (low-frequency) catecholamine secretion is unaffected. These experiments appear to satisfy the criterion for PACAP as the neurotransmitter responsible for stress transduction at the adrenomedullary synapse (see Figure $2 \mathbf{A}$ ) $(31,32)$.

How generalizable is the concept that PACAP, and not acetylcholine, is the major autonomic stress neurotransmitter? This involves answering two questions. First, in how many other mammalian species is PACAP the splanchnicoadrenomedullary transmitter? Second, is PACAP the stress transducing transmitter at other autonomic synapses of the sympathetic and parasympathetic nervous systems? With respect to the 


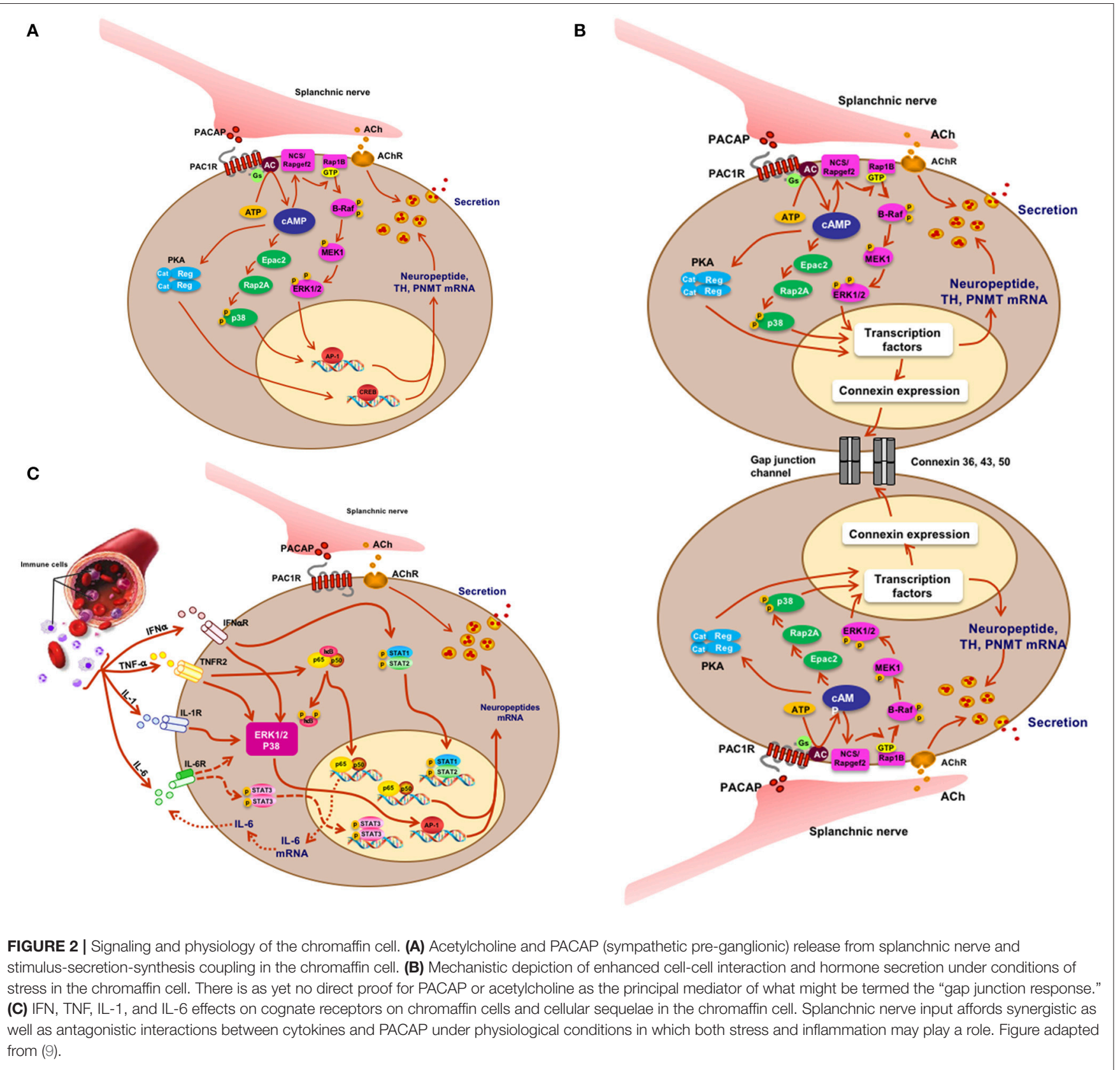

first question, catecholamine secretion is provoked by PACAP, either in vivo or in chromaffin cells in culture, in all mammals examined so far, including mice, rats, cows, dogs, and humans [reviewed in (27)]. Regarding the second, there is a significant body of evidence for receptivity of sympathetic post-ganglionic neurons, in culture, to PACAP, as evidenced by enhanced secretion as well as signaling for gene expression $(33,34)$. Post-ganglionic neurons of the system, notably in the heart, are also PACAP responsive (35). Thus, findings in the findings in the adrenal medulla likely herald a new perspective in adding the neuropeptide PACAP as the third major neurotransmitter of the autonomic nervous system, in addition to acetylcholine and norepinephrine.

\section{Gs-GPCR SIGNALING FOR SECRETION AND BIOSYNTHESIS IN THE CHROMAFFIN CELL}

Hormone-secreting endocrine tissues must maintain their stores of secreted material, catecholamines from chromaffin cells, insulin from beta cells of the pancreas, hypophyseal hormones from their depots in anterior pituitary cells, incretins from endocrine cells of the gut, and so forth, in order to maintain patency for future endocrine response. This can occur via parallel but uncoupled processes if hormone secretion and biosynthesis both occur at about the same constitutive rate, but this is rarely the case, as hormone secretion tends to be episodic 
in response to metabolic and other homeostatic organismic demands, when the endocrine cell is called upon by first messenger secretagogues to release its characteristic hormone into the bloodstream to act at distant sites. Timely repletion of hormone content in endocrine tissue following a bout of secretion in these cases can occur in one of two ways. The first is a chronic overproduction of prohormone protein by the endocrine cell relative to storage capacity. In this case, excess hormone is degraded at times of low secretory demand, and diverted to the secretory pathway at times of high secretory demand. This type of regulation appears to be the case for chromogranin A in adrenal medulla: because chromogranin A is a constituent of secretory granule biogenesis itself, the chromaffin cell makes no more chromogranin than it does secretory granules. When the secretory granule complement is complete, excess chromogranin is apparently degraded in the trans-Golgi network and when the granule complement is depleted by a bout of secretion, this excess is re-directed toward granule production, so that chromogranin levels are maintained during secretion even when there is no compensatory up-regulation of chromogranin mRNA abundance compared to that of other co-secreted neuropeptides $(36,37)$. For (pro)hormones that are only a fraction of the total secretory granule protein content, however, a non-default regulatory mechanism for compensating hormone loss through secretion with enhanced biosynthesis must exist (this actually includes chromogranins themselves, in cells in which they are not the dominant secreted protein).

The concept of stimulus-secretion-synthesis coupling was introduced into the neuroendocrine lexicon with the realization that first messengers that act as secretagogues, facilitating the release of stored hormones into the bloodstream, may simultaneously signal to the endocrine cell to engage the genetic machinery that allows repletion of hormone (38). For hormones that are produced by prohormone processing within the secretory granule, this is reflected in enhanced transcription of the prohormone gene and subsequently enhanced translation of its mRNA into prohormone protein. In the adrenal medulla, in which secreted material is a mixture of protein (chromogranins and neuropeptides) and small molecules (catecholamines and ATP), stimulus-secretion synthesis coupling must accommodate both types of secreted material. Thus, secretagogue (firstmessenger) signaling leads immediately to calcium influx, then to activation of the secretory apparatus and release from the cell of the contents of the secretory vesicle/granule. Simultaneously, downstream signaling from the first messenger must engage pathways leading to (i) stimulation of transcription of prohormone protein-encoding genes and (ii) stimulation of biosynthetic enzymes responsible for catecholamine and other small-molecule biosynthesis. In the case of catecholamine production, this means activation of both the enzymatic activity, via phosphorylation, of the rate-limiting enzyme for catecholamine biosynthesis, tyrosine hydroxylase (TH) and increased production of the $\mathrm{TH}$ protein itself, via increased transcription from the $\mathrm{TH}$ gene (39).

The detailed cellular mechanisms of signaling for hormone repletion in the adrenal medulla was much-studied throughout the Twentieth century and in many ways was paradigmatic for understanding this process in other endocrine cells and tissues. The second messenger most often evoked as mediating stimulussynthesis coupling is calcium, the same second messenger that triggers secretin in most endocrine cells. However, in the adrenal medulla, cyclic AMP was implicated early on in both transcriptional and post-translation effects on $\mathrm{TH}$ activation. Later, examination of stimulus-secretion-synthesis coupling related to co-stored peptides such as substance P, NPY, enkephalin, and galanin revealed that while cyclic AMP appears (as in anterior pituitary cells such as corticotropes) to be the main second messenger for activation of gene transcription of the latter, the classical pathway to cAMP-dependent gene activation by the third messenger protein kinase A (PKA) was insufficient to explain how this signaling could occur.

The concept that cAMP's actions are mediated solely through activation of the serine/threonine protein kinase protein kinase A (PKA) was a durable one for several decades after its promulgation by Kuo and Greengard (40). However, toward the end of the Twentieth century it became increasingly apparent that not only could cAMP gate calcium channels on the surface of specialized cells, such as those of the olfactory mucosa (41), but that there were a plethora of CAMP-dependent and PKAindependent actions of first messengers that strongly suggested the existence of other cAMP effectors within mammalian, especially neuroendocrine cells. In the late 90s, two groups discovered two proteins among a family of Rapgef proteins (for guanine nucleotide exchange factors activating the signaling kinase Rap), variously called Epac1 and 2 (the currently most common name), or Rapgef3 and 4, or cAMP-GEF1 and -2 (42-44). These proteins clearly expanded the range of cAMP effectors within mammalian cells from protein kinases to guanine nucleotide exchange factors, with their own sets of downstream effectors (mainly MAP kinases) distinct from cytoplasmic substrates such as glycogen synthase, and nuclear transcription factors such as CREB, activated by PKA.

Our own laboratory noted in 2012 that galanin biosynthesis in the chromaffin cell was regulated by the stress-associated secretagogue PACAP, via a cyclic AMP signaling pathway independent of PKA, and requiring activation of the MAP kinase ERK (45). The cAMP effector linking activation of adenylate cyclase and ERK by PACAP was identified by both loss- and gain-of-function experiments, in cellula, as the gene product of the guanine nucleotide exchange factor Rapgef2 (46). This enzyme had been deemed to be insensitive to regulation by cAMP by both in vitro biochemical criteria and by sequence comparison to known cAMP binding proteins $(47,48)$. However, others had identified Rapgef 2 as a cyclic nucleotide-regulated protein in neuroendocrine (melanoma) cells $(49,50)$. We have subsequently identified two mRNA variants transcribed from the Rapgef2 gene, which we have termed NN (for non-neuronal)Rapgef2 and NCS (for neuritogenic cAMP sensor)-Rapgef2. The latter transcript appears to be generated exclusively in neuronal and endocrine cell types/tissues in adult rodents, and is responsible for linking cAMP elevation and ERK activation not only in chromaffin cells, but in neurons of the central nervous system (51). Re-assessment of cAMP signaling with respect to its parcellation between protein kinase $\mathrm{A}$, and the guanine 
nucleotide exchange factors Epac and NCS-Rapgef2, is likely to occur throughout the field of endocrinology in the coming years. The characterization of the cellular assignments of these three cAMP effectors in signaling not only within the adrenal medulla, but in anterior pituitary, pancreatic islets, enterochromaffin cells, and other endocrine and neuronal cells is presently underway in several laboratories (51-56).

\section{THE ROLE OF PEPTIDES SECRETED FROM THE ADRENAL MEDULLA}

As mentioned previously, the finding that the adrenal medulla secretes bioactive neuropeptides in addition to catecholamines was a major development for neurochemistry and neuroendocrinology in the early 1980s, and in fact paved the way for the discovery of the mRNAs encoding the opiate peptides (57-60). Its historical roots exist in the discovery of the chromogranins as secreted proteins of the adrenal medulla (vida infra); the discovery that enkephalin peptides are a major constituent of the secretory granules of the adrenal medulla (57, 58); and the realization that chromogranin $\mathrm{A}$ is itself a prohormone for bioactive peptides including pancreastatin, vasostatin, catestatin, and others (61-64). The adrenal medullaspecific proenkephalin-derived BAM-22P was identified via systematic peptidomics analysis of the adrenal medullary "peptide storehouse" (65). Adrenomedullin was discovered via a specific proteomics-based search for novel cAMPelevating neuropeptides in pheochromocytoma peptide extracts (66). The presence of a rich secretory cocktail, comprising the chromogranin-derived, enkephalin-derived, and other neuropeptides, as well as the neuropeptides substance $\mathrm{P}$, galanin, and NPY raised the important question of what the function of such released peptides might be. The answer(s) to these questions was initially frustrated by a lack of knowledge about where the corresponding receptors for peptides exist, and thus whether they were most likely to play an autocrine, paracrine, or hormonal function in vivo (63). The molecular nature of the receptor for catestatin, one of the $\mathrm{CgA}$-derived peptides of the adrenal medulla, is still uncertain. However, O'Connor and colleagues were able to show convincingly that catestatin is able to modulate acetylcholine-induced catecholamine secretion from chromaffin cells, without affecting secretion caused by potassium or barium depolarization or ionophore-stimulated release, suggesting that its receptor either is, or acts immediately downstream of, the cholinergic nicotinic receptor of the chromaffin cell (67). More recently, it has been demonstrated in PC12 cells that catestatin affects not only acetylcholine-induced but also PACAP-induced catecholamine secretion, making its role in stress-related as well as basal adrenomedullary function of likely physiological importance (68). Likewise, substance $\mathrm{P}$ has been proposed as an autocrine regulator of catecholamine secretion and biosynthesis, based on its negative modulation of nicotinic receptor activation in chromaffin cells (69-71).

Catestatin, however, is truly protean in its autocrine and hormonal roles throughout the body. Perhaps the most striking finding about catestatin is its ability to rescue a chromogranin
A-deficient phenotype in mice (72). Catestatin/chromograninmediated effects permeate all functions of the adrenal chromaffin cell (72). This includes the formation of secretory granules themselves (73), although this function appears to be shared with other granin proteins in chromaffin cells (74), and modulation of catecholamine release (75). Physiologically, catestatin extends the range of the adrenal medulla as an endocrine organ beyond the scope of catecholamine effects on cardiovascular function and metabolism, to endocrine (catestatin) modulation of the secretion, metabolism, and morphology of endocrine cells which are its targets (including the chromaffin cell) as well as its effects on modulation of beta cell function, immune regulation, and muscle and neuronal cellular metabolism $(76,77)$. As well, several other chromogranin A-derived peptides, including vasostatin, have potent cardiovascular effects that make the adrenal medulla a multi-pronged regulator of cardiovascular as well as metabolic function, and therefore link stress transduction even more tightly to cardiovascular and metabolic physiology (78).

The protean role of chromogranin-derived peptides, at every level of adrenomedullary function, has opened up an important chapter of endocrinology by sharpening appreciation for the role of peptide hormones, and their receptors, as highly adaptive components of the evolution of the endocrine network through constant adaptation of peptides to new regulatory roles, especially through tissue-specific expression of various peptides due to cell-specific prohormone processing. Such is the case of BAM22P. This 22-amino acid proenkephalin-derived peptide (YGGFMRRVGRPEWWMDYQKRYG) is found almost exclusively in the adrenal medulla, most likely because the only partial processing of proenkephalin in the adrenal gland, unlike in neuronal cells, results in a plethora of "incompletely" processed peptides. These however, are not only intermediates. Only distantly related to the mu opiate receptor, which is mainly liganded by leu- and met-enkephalin in vivo, the BAM22P receptor shows a more than 50-fold higher affinity for BAM22P than for met-enkephalin, which is contained within the primary sequence of the BAM22P peptide (79). The exclusive presence of the BAM22P receptor in sensory neurons, and the high levels of BAM22P in adrenal medulla, suggests that this peptide may be a specific first messenger for adrenomedullary communication with sensory nerves that abundantly innervate the adrenal gland (Figure 1). A link between the major stress-transducing endocrine organ, the adrenal medulla, and the sensory nervous system at this anatomical locus is intriguing to consider.

\section{THE CONCEPT OF ORGAN PLASTICITY IN STRESS RESPONDING OF THE ADRENAL MEDULLA}

It is by now well-known that endocrine tissues develop as "colonies" of cells devoted to a single secretory mission, but it was initially thought that each cell within this colony acts more-or-less independently of its neighbors in responding to first-messenger secretagogues with hormone release: a massively parallel rather than a highly integrated response. In the secretion of vasopressin, however, several investigators promulgated the 
concept of "concerted" actions of the entire secretory cell cohort (80). This seemed to account for the dynamics of secretion in this system more comprehensively, and mechanisms of this type are now being explored and discovered in other cell types. "Concerted secretion" could occur by one of two (or both) mechanisms. One of these is paracrine/autocrine regulation, in which substances secreted from a single secretory cell interact with receptors on the same cell (autocrine regulation) or neighboring cells of the same (also autocrine) or another (paracrine) type, to modulate their secretion. In any event, the concept of autocrine/paracrine regulation was easily applied to the adrenal medulla, in part to explain the actions of hormones besides catecholamines (see previous section) which appeared to be released from the adrenal medulla in too low levels to be bona fide hormones, thus begging for an additional function to explain their production in and secretion from chromaffin cells. A second mode of modulating the secretory response of endocrine cells as an organ collective consists in stimulus-dependent changes in cellular adhesion mediating cell-cell interactions called gap junctions that can affect secretory performance (Figure 2B). Gap junctions are electrical connections that lower the resistance between cells that are connected by them. Connexins are the proteins that make up the hexameric hemichannels that form gap junctions: when two hemichannels on adjacent cells are apposed, a gap junction is formed. In 2001 Martin et al. (81) made the seminar observation that connexins are expressed by rat adrenal chromaffin cells. The history of the gap junction in adrenal medulla and other endocrine tissues is capably summarized by Colomer et al. (82): suffice it to say here that the initial demonstration of the chromaffin cell gap channel was facilitated initially by the realization that the disparate cellular resistances of isolated chromaffin cells in culture are considerably greater than those of chromaffin cells in intact adrenomedullary cells, with these differences in input resistance logically inferred to arise from the existence of gap junctions between the latter and not the former $(81,83)$. A series of in vivo experiments have been performed by the Guerineau laboratory to assess the role(s) of gap junctions in adrenomedullary function in vivo [summarized in (84)]. Rat adrenomedullary slices were examined ex vivo both before and after 5 days of cold stress (85). Morphological remodeling of both splanchnicoadrenomedullary synapses and chromaffin cells at their borders of adjacency was observed, along with increased dye permeation between cells at gap junctions, and increased electrical coupling following exogenous depolarization of individual chromaffin cells. Further experiments have indicated that stress in vivo causes increased catecholamine secretion in response to electrical stimulation that is blocked by pharmacological inhibition of gap junction formation. Detail of biochemical constitution of gap junctions, and gap-junction dependence of stress-induced enhancement of catecholamine secretion from chromaffin cells in vivo have followed $(82,86)$. Clearly there is, in addition to a shift from predominantly cholinergic to PACAPergic neurotransmission at the adrenomedullary synapse from rest to stress upon initial exposure to stressors, a profound reorganization of the gland itself that prepares it to anticipate further challenge by stress, and/or to protect the integrity of the gland from deleterious effects of increased functional load. At this time, it is unclear whether acetylcholine, PACAP or a combination of the two transmitters mediates this organotypic adaptive response.

The role of gap junctions in adrenomedullary function is likely to be a generalizable phenomenon, not only to other endocrine organs (87) but also to neuronal communication: the stress stimulus selected by Guerineau for analysis of the adrenal medulla is one that is relatively slight for that organ (88) but plays a major role in regulation of norepinephrine output from post-ganglionic sympathetic nerves. It remains to be seen if principal ganglion cells of the sympathetic nervous system respond to stress as the adrenal medulla does, and if PACAP, or acetylcholine, or both are the principal regulator(s) of this important phenomenon. Of utmost importance, this work in aggregate reminds investigators of the limitations of studying endocrine phenomena in isolated cells, in which there is much insight to be gained, but in which much about how endocrine tissues actually function in vivo can be overlooked.

\section{ADRENOMEDULLARY FUNCTION DURING INFLAMMATORY RESPONSES}

The inflammatory response is complex and involves virtually all organs, as cytokines are both secreted into the bloodstream and affect tissues hormonally, and because cytokine-secreting cells of the immune system are mobile and ubiquitous, migrating to various locations in response to local and systemic inflammatory challenge. The discovery of LPS and cytokine receptors on chromaffin cells was a key event in focusing on the role of the adrenal medulla in coordinating some aspects of the immune response (Figure 1). Working out the pathways for cytokine signaling and its ramifications for chromaffin cell parachymal function, and adrenomedullary participation in systemic inflammation, has been an intriguing enterprise, and worth noting within the purview of "what's new in endocrinology."

It was noted a number of years ago that neuropeptide biosynthesis is complexly modulated by the cytokines IL-1 and TNF-alpha in bovine chromaffin cells in culture, with positive regulation of VIP biosynthesis and down-regulation of metenkephalin, and amplification of the effects of cyclic AMP elevation on VIP and substance P production by both cytokines (89). More recently, Anouar and colleagues demonstrated the existence of TNF-alpha receptor expression in the bovine adrenal medulla in vivo $(90,91)$, and the regulation of gene transcription and peptide production of galanin and chromogranin in response to this cytokine (91). Subsequently, Bunn and colleagues postulated a role for TNF in inflammation-induced VIP biosynthesis and $\mathrm{TH}$ induction in rodent adrenal medulla in vivo $(9,92)$. A number of other studies converge to create a picture of cytokine regulation of adrenomedullary peptide production for a counter-regulatory role in inflammation: exposure of chromaffin cells to cytokines or administration of LPS in vivo (S. Bunn, personal communication) results in enhanced production of galanin, which is reported in turn to be a positive regulator of 
glucocorticoid production in the adrenal cortex (see Figure 2C). The inflammatory cytokines IL-1 and TNF (9) also increase the production of IL- 6 mRNA in chromaffin cells, revealing an occult source of this anti-inflammatory peptide that implicates a second mechanism of down-regulation of the "cytokine storm" associated with inflammation. This anti-inflammatory mechanism is also linked to the stress-transducing function of the adrenal gland, emphasizing further the highly integrative role of the adrenal medulla as stress transducer across multiple other (metabolic, neuronal, immune) endocrine regulatory domains (Figures 1, 2).

\section{SUMMARY AND FUTURE PROSPECTS}

The simple and classical view that the adrenal medulla releases catecholamines under stress in response to acetylcholine release from the splanchnic nerve provided a framework for much fruitful investigation of the detailed cellular physiology underlying the function of the chromaffin cell. This view has been enriched over the past 20 years, as summarized in Figures 1, 2. The adrenal medulla is now viewed as a more complex, and more integrative, stress transducer. Basal secretion, under the influence solely of acetylcholine, is seen as important to cardiovascular function as well. Additional first messengers besides acetylcholine, including PACAP and cytokines, bring organismic information to the chromaffin cell. The secretory products of the chromaffin cells also have important, yetto-be-discovered paracrine, autocrine and hormonal roles. These allow integration of immune, inflammatory, sensory, and cardiovascular surveillance and regulation by the adrenal medulla. Chromaffin cells themselves not only operate as individual cellular elements that amplify signal transduction by being organized into an endocrine organ, but also modulate the performance of this cellular cohort by chromaffin cellchromaffin cell coordination through gap junctions. Each of these themes is likely to be generalizable to other endocrine organs to some degree: PACAP at sympathetic ganglia as well as the sympathoadrenal junction; cytokine regulation of other peripheral endocrine depots such as the pancreas; gap junction function in pituitary and likely elsewhere; parcellated cAMP signaling in pancreas and brain as well as the adrenal; catestatin function throughout the cardiovascular system. Leveraging the sense that 'everything is connected to everything else' (93) does not mean, however, that the mammalian endocrine network is chaotic, or therapeutically opaque. Rather, apprehending directionality in endocrine regulation probably requires a better sense of what is unique about each endocrine organ, including the adrenal medulla, in addition to the predominant hormone that is released from it.

\section{REFERENCES}

1. Andreis PG, Tortorella C, Ziolkowska A, Spinazzi R, Malendowicz LK, Neri G, et al. Evidence for a paracrine role of endogenous adrenomedullary galanin in the regulation of glucocorticoid secretion in the rat adrenal gland. Int J Mol Med. (2007) 19:511-5. doi: 10.3892/ijmm.19. 3.511
Some rather large questions remain, both about the adrenal medulla in particular, and its characteristics as an endocrine organ in general. What are the ways in which acetylcholine and PACAP collaborate in adrenomedullary function in homeostasis and stress responding? Are these two messengers specialized for "basal" or "rest and digest" vs. "stress" or "fight or flight" responding, or is their interaction more intricate than that? Does acetylcholine/PACAP co-transmission contribute importantly to transmission elsewhere in the autonomic nervous system, i.e., at both sympathetic and parasympathetic synapses? Is the adrenomedullary stress response "looped in" to both the immune-inflammatory and sensory nervous systems? Might this be a potential key to immune and sensory regulation in stress and the balance between pro- and anti-inflammatory regulation that allows glucocorticoids and cytokines to counter-balance without either being overcome in sepsis or autoimmune dysregulation? Might signaling via catestatin, BAM-22P, substance P, galanin and other secretory products of the adrenal medulla lead to regulatory sequelae that can be exploited in disease treatment? Are the signaling mechanisms newly discovered in the adrenal medulla generalizable to other endocrine organs and even the nervous system? Is metabologenomics of the chromaffin cell a paradigm that will create diagnostic/prognostic opportunities for endocrinopathies beyond pheochromocytoma $(94,95)$ ? Finally, we would be remiss not to note again that the adrenal medulla is an organ with pronounced mammalian species differences: how much of what we have learned about its function in rodents and other mammals is directly applicable to H. sapiens? It is our hope that this bouquet of questions will stimulate further research leading to the discovery of new aspects of chromaffin cell function. These in turn will beget additional questions, keeping the adrenal medulla at the forefront of endocrinology, despite our recurrent conviction that we know all we need to know about this deceptively simple endocrine organ.

\section{AUTHOR'S NOTE}

Much of the content of this review concerns work performed in our own and colleagues' laboratories and its precedents that are only now emerging in the literature. We apologize in advance for any myopia about progress in chromaffin cell endocrinology emerging from other laboratories that this review may have overlooked.

\section{AUTHOR CONTRIBUTIONS}

All authors listed have made a substantial, direct and intellectual contribution to the work, and approved it for publication.

2. Mazzocchi G, Malendowicz LK, Rebuffat P, Gottardo L, Nussdorfer GG. Expression and function of vasoactive intestinal peptide, pituitary adenylate cyclase-activating polypeptide, and their receptors in the human adrenal gland. J Clin Endocrinol Metab. (2002) 87:2575-80. doi: 10.1210/jcem.87.6.8571

3. Spinazzi R, Andreis PG, Nussdorfer GG. Neuropeptide-Y and Y-receptors in the autocrine-paracrine regulation of adrenal gland under physiological 
and pathophysiological conditions (Review). Int J Mol Med. (2005) 15:3-13. doi: $10.3892 / \mathrm{ijmm} .15 .1 .3$

4. Nussdorfer GG. Paracrine control of adrenal cortical function by medullary chromaffin cells. Pharmacol Rev. (1996) 48:49 $5-530$.

5. Bornstein SR, Haidan A, Ehrhart-Bornstein M. Cellular communication in the neuroadrenocortical axis: Role of vasoactive intestinal polypeptide (VIP). Endocrine Res. (1996) 22:819-29.

6. Bornstein SR, Rutkowski H, Vrezas I. Cytokines and steroidogenesis. Mol. Cell. Endocrinol. (2004) 215:135-41. doi: 10.1016/j.mce.2003. 11.022

7. Path G, Bornstein SR, Ehrhart-Bornstein M, Scherbaum WA. Interleukin6 and the interleukin- 6 receptor in the human adrenal gland: expression and effects on steroidogenesis. J Clin Endocrinol Metab. (1997) 82:2343-9. doi: $10.1210 /$ jcem.82.7.4072

8. Ehrhart-Bornstein M, Hinson JP, Bornstein SR, Scherbaum WA, Vinson GP. Intraadrenal interactions in the regulation of adrenocortical steroidogenesis. Endocr Rev, (1998) 19:101-43. doi: 10.1210/edrv.19.2.0326

9. Bunn SJ, Ait-Ali D, Eiden LE. Immune-neuroendocrine integration at the adrenal gland: cytokine control of the adrenomedullary transcriptome. J Mol Neurosci. (2012) 48:413-9. doi: 10.1007/s12031-012-9745-1

10. Coupland RE. Electron microscopic observations on the structure of the rat adrenal medulla. The ultrastructure, I. and organization of chromaffin cells in the normal adrenal medulla. J Anat. (1965) 99: 231-54.

11. Hillarp NA. Isolation and some biochemical properties of the catechol amine granules in the cow adrenal medulla. Acta Physiol Scand. (1958) 43:82-96. doi: 10.1111/j.1748-1716.1958.tb01579.x

12. Winkler H, Fischer-Colbrie R. The chromogranins A and B: the first 25 years and future perspectives. Neuroscience (1992) 49:497-528. doi: 10.1016/0306-4522(92)90222-N

13. Helle KB. The granin family of uniquely acidic proteins of the diffuse neuroendocrine system: comparative and functional aspects. Biol Rev Camb Philos Soc. (2004) 79:769-94. doi: 10.1017/S146479310400644X

14. Douglas WW, Rubin RP. The role of calcium in the secretory response of the adrenal medulla to acetylcholine. J Physiol. (1961) 159:40-57. doi: 10.1113/jphysiol.1961.sp006791

15. Douglas WW. Stimulus-secretion coupling: The concept and clues from chromaffin and other cells. Br J Pharmacol. (1968) 34:451-74. doi: 10.1111/j.1476-5381.1968.tb08474.x

16. Marley PD. Desensitization of the nicotinic secretory response of adrenal chromaffin cells. Trends Pharmacol Sci. (1988) 9:102-7. doi: 10.1016/0165-6147(88)90177-0

17. Wakade AR, Wakade TD, Malhotra RK. Restoration of catecholamine content of previously depleted adrenal medulla in vitro: importance of synthesis in maintaining the catecholamine stores. J Neurochem. (1988) 51:820-29. doi: 10.1111/j.1471-4159.1988.tb01817.x

18. Chuang DM, Costa E. Biosynthesis of tyrosine hydroxylase in rat adrenal medulla after exposure to cold. Proc Natl Acad Sci USA. (1974) 71: $4570-4$.

19. Evinger MJ, Ernsberger P, Regunathan S, Joh TH, Reis DJ. A single transmitter regulates gene expression through two separate mechanisms: cholinergic regulation of phenylethanolamine N-methyltransferase mRNA via nicotinic and muscarinic pathways. J Neurosci. (1994) 14:2106-16. doi: 10.1523/JNEUROSCI.14-04-02106.1994

20. Thoenen H, Mueller RA, Axelrod J. Trans-synaptic induction of adrenal tyrosine hydroxylase. J Pharm Exp Ther. (1969) 169:249-54.

21. Ip NY, Perlman RL, Zigmond RE. Acute transsynaptic regulation of tyrosine 3-monooxygenase activity in the rat superior cervical ganglion: evidence for both cholinergic and noncholinergic mechanisms. Proc Natl Acad Sci USA. (1983) 80:2081-85. doi: 10.1073/pnas.80.7.2081

22. Miyata A, Arimura A, Dahl RR, Minamino N, Uehara A, Jiang L, et al. Isolation of a novel 38 residue-hypothalamic polypeptide which stimulates adenylate cyclase in pituitary cells. Biochem Biophys Res Commun. (1989) 164:567-74. doi: 10.1016/0006-291X(89)91757-9

23. Arimura A, Pituitary Adenylate Cyclase-Activating Polypeptide (PACAP): discovery and current status of research. Regul. Pept. (1992) 37:287-303. doi: 10.1016/0167-0115(92)90621-Z
24. Edwards AV, Jones CT. Adrenal cortical and medullary responses to acetylcholine and vasoactive intestinal peptide in conscious calves. J Physiol. (1993) 468:515-27. doi: 10.1113/jphysiol.1993.sp019785

25. Geng G, Gaspo R, Trabelsi F, Yamaguchi N. Role of L-type Ca2+ channel in PACAP-induced adrenal catecholamine release in vivo. Am J Physiol. (1997) 42:R1339-45. doi: 10.1152/ajpregu.1997.273.4.R1339

26. Lamouche S, Martineau D, Yamaguchi N. Modulation of adrenal catecholamine release by PACAP in vivo. Regul Integr Comp Physiol. (1999) 45:R162-70. doi: 10.1152/ajpregu.1999.276.1.R162

27. Hamelink C, Weihe E, Eiden LE. PACAP: an "emergency response" cotransmitter in the adrenal medulla. In: Vaudry H. Arimura A, editors. Pituitary Adenylate Cyclase-Activating Polypeptide. Norwell, MA: Kluwer-Academic Press (2003), p. 227-50.

28. Hamelink C, Tjurmina O, Damadzic R, Young WS, Weihe E, Lee HW, et al. Pituitary adenylate cyclase activating polypeptide is a sympathoadrenal neurotransmitter involved in catecholamine regulation and glucohomeostasis. Proc Natl Acad Sci USA. (2002) 99:461-66. doi: $10.1073 /$ pnas. 012608999

29. Stroth N, Kuri BA, Mustafa T, Chan SA, Smith CB, Eiden LE et al. PACAP controls adrenomedullary catecholamine secretion and expression of catecholamine biosynthetic enzymes at high splanchnic nerve firing rates characteristic of stress transduction in male mice. Endocrinology (2013) 154:330-9. doi: 10.1210/en.2012-1829

30. Kuri BA, Chan SA, Smith CB. PACAP regulates immediate catecholamine release from adrenal chromaffin cells in an activity-dependent manner through a protein kinase C-dependent pathway. J Neurochem (2009) 110:1214-25. doi: 10.1111/j.1471-4159.2009.06206.x

31. Smith CB, Eiden LE. Is PACAP the major neurotransmitter for stress transduction at the adrenomedullary synapse? J Mol Neurosci. (2012) 48:40312. doi: $10.1007 / \mathrm{s} 12031-012-9749-\mathrm{x}$

32. Eiden LE, Emery AC, Zhang L, Smith CB. PACAP signaling in stress: insights from the chromaffin cell. Pflugers Arch. (2018) 470:79-88. doi: 10.1007/s00424-017-2062-3

33. Beaudet MM, Parsons RL, Braas KM, May V. Mechanisms mediating pituitary adenylate cyclase-activating polypeptide depolarization of rat sympathetic neurons. J Neurosci. (2000) 20:7353-61. doi: 10.1523/JNEUROSCI.20-19-07353.2000

34. May V, Beaudet MM, Parsons RL, Hardwick JC, Gauthier EA, Durda JP, et al. Mechanisms of pituitary adenylate cyclase activating polypeptide (PACAP)-induced depolarization of sympathetic superior cervical ganglion (SCG) neurons. Ann N Y Acad Sci. (1998) 865:164-75. doi: $10.1111 / j .1749-6632.1998 . t b 11175 . x$

35. Tompkins JD, Ardell JL, Hoover DB, Parsons RL. Neurally released pituitary adenylate cyclase-activating polypeptide enhances guinea pig intrinsic cardiac neurone excitability. J Physiol. (2007) 582:87-93. doi: 10.1113/jphysiol.2007.134965

36. Eiden LE, Iacangelo A, Hsu CM, Hotchkiss AJ, Bader MF, Aunis D. Chromogranin A synthesis and secretion in chromaffin cells. J. Neurochem. (1987) 49:65-74.

37. Fischer-Colbrie R, Iacangelo A, Eiden LE. Neural and humoral factors separately regulate neuropeptide Y, enkephalin, and chromogranin A and B mRNA levels in rat adrenal medulla. Proc Natl Acad Sci USA. (1988) 85:3240-4.

38. Eiden LE, Giraud P, Dave JR, Hotchkiss AJ, Affolter HU. Nicotinic receptor stimulation activates both enkephalin release and biosynthesis in adrenal chromaffin cells. Nature (1984) 312:661-3. doi: 10.1038/312 $661 \mathrm{a} 0$

39. Haycock JW, Wakade AR. Activation and multiple-site phosphorylation of tyrosine hydroxylase in perfused rat adrenal glands. J Neurochem. (1992) 58:57-64. doi: 10.1111/j.1471-4159.1992.tb09276.x

40. Kuo JF, Greengard P. Cyclic nucleotide-dependent protein kinases. IV. Widespread occurrence of adenosine $3^{\prime}, 5^{\prime}$-monophosphate-dependent protein kinase in various tissues and phyla of the animal kingdom. Proc Natl Acad Sci USA. (1969) 64:1349-55. doi: 10.1073/pnas.64. 4.1349

41. Brown RL, Strassmaier T, Brady JD, Karpen JW. The pharmacology of cyclic nucleotide-gated channels: emerging from the darkness. Curr Pharm Des. (2006) 12:3597-613. doi: 10.2174/138161206778522100 
42. de Rooij J, Zwartkruis FJ, Verheijen MH, Cool RH, Nijman SM, Wittinghofer A. Epac is a Rap1 guanine-nucleotide-exchange factor directly activated by cyclic AMP. Nature (1998) 396:474-7.

43. Bos JL. Epac: a new cAMP target and new avenues in cAMP research. Nat Rev Mol Cell Biol. (2003) 4:733-8. doi: 10.1038/nrm1197

44. Kawasaki H, Springett GM, Mochizuki N, Toki V, Nakaya V, Matsuda M, et al. A family of cAMP-binding proteins that directly activate Rap1. Science (1998) 282:2275-9. doi: 10.1126/science.282.5397.2275

45. Emery AC, Eiden LE. Signaling through the neuropeptide GPCR PAC1 induces neuritogenesis via a single linear cAMP- and ERK-dependent pathway using a novel cAMP sensor. FASEB J. (2012) 26:3199-211. doi: 10.1096/ff.11-203042

46. Emery AC, Eiden MV, Mustafa T, Eiden LE. Rapgef2 connects GPCRMediated cAMP signals to ERK activation in neuronal and endocrine cells. Sci Signal. (2013). 6:ra51. doi: 10.1126/scisignal.2003993

47. Kuiperij HB, de Rooij J, Rehmann H, van Triest M, Wittinghofer A, Bos JL, et al. Characterisation of PDZ-GEFs, a family of guanine nucleotide exchange factors specific for Rap1 and Rap2. Biochim Biophys Acta. (2003) 1593:141-9. doi: 10.1016/S0167-4889(02) 00365

48. Kannan N, Wu J, Anand GS, Yooseph S, Neuwald AF, Venter JC, et al. Evolution of allostery in the cyclic nucleotide binding module. Genome Biol. (2007) 8:R264. doi: 10.1186/gb-2007-8-12-r264

49. Pham N, Cheglakov I, Koch CA, de Hoog CL, Moran MF, Rotin $\mathrm{D}$, et al. The guanine nucleotide exchange factor CNrasGEF activates ras in response to cAMP and cGM. Curr Biol. (2000) 10:555-8. doi: 10.1016/S0960-9822(00)00473-5

50. Amsen EM, Pham N, Pak Y, Rotin D. The guanine nucleotide exchange factor CNrasGEF regulates melanogenesis and cell survival in melanoma cells. J Biol Chem. (2006) 281:121-8. doi: 10.1074/jbc.M507595200

51. Jiang SZ, Xu W, Emery AC, Gerfen CR, Eiden MV, Eiden LE. NCS-Rapgef2, the protein product of the neuronal Rapgef2 Gene, is a specific activator of D1 dopamine receptor-dependent ERK phosphorylation in mouse brain. eNeuro (2017) 4:1-17. doi: 10.1523/ENEURO.0248-17.2017

52. Holz GG, Kang G, Harbeck M, Roe MW, Chepurny OG. Cell physiology of cAMP sensor Epac. J Physiol. (2006) 577:5-15. doi: 10.1113/jphysiol.2006.119644

53. Lopez De Jesus M, Stope MB, Oude Weernink PA, Mahlke Y, Börgermann C, Ananaba VN, et al. Cyclic AMP-dependent and Epac-mediated activation of R-Ras by G protein-coupled receptors leads to phospholipase D stimulation. J Biol Chem. (2006) 281:21837-47. doi: 10.1074/jbc.M6041 56200

54. Keiper M, Stope MB, Szatkowski D, Bohm A, Tysack K, Vom Dorp F, et al. Epac- and $\mathrm{Ca} 2+-$ controlled activation of Ras and extracellular signalregulated kinases by Gs-coupled receptors. J Biol Chem. (2004) 279:46497508. doi: 10.1074/jbc.M403604200

55. Roscioni SS, Elzinga CR, Schmidt M. Epac: effectors and biological functions. Naunyn Schmiedebergs Arch Pharmacol. (2008) 377:345-57. doi: 10.1007/s00210-007-0246-7

56. Emery AC, Liu XH, Xu W, Eiden MV, Eiden LE. Cyclic adenosine 3',5'monophosphate elevation and biological signaling through a secretin family Gs-coupled G protein-coupled receptor are restricted to a single adenylate cyclase isoform. Mol Pharmacol. (2015) 87:928-35. doi: 10.1124/mol.115.098087

57. Livett BG, Dean DM, Whelan LG, Udenfriend S, Rossier J. Co-release of enkephalin and catecholamines from cultured chromaffin cells. Nature (1981) 289:317-9.

58. Lewis RV, Stern AS, Kilpatrick DL, Gerber LD, Rossier J, Stein S et al. Marked increases in large enkephalin-containing polypeptides in the rat adrenal gland following denervation. J Neurosci. (1981) 1:80-82.

59. Comb M, Seeburg PH, Adelman J, Eiden L, Herbert E. Primary structure of the human Met- and Leu-enkephalin precursor and its mRNA. Nature (1982) 295:663-6.

60. Lewis RV, Stern AS, Kimura S, Rossier J, Stein S, Udenfriend S. An about 50,000-dalton protein in adrenal medulla: a common precursor of [Met]- and [Leu] enkephalin. Science (1980) 208:1459-61.

61. Eiden LE. Is chromogranin a prohormone? Nature (1987) 325:301. doi: $10.1038 / 325301 \mathrm{a} 0$
62. Taylor CV, Taupenot L, Mahata SK, Mahata M, Wu H, Yasothornsrikul $\mathrm{S}$, et al. Formation of the catecholamine release-inhibitory peptide catestatin from chromogranin A. Determination of proteolytic cleavage sites in hormone storage granules. J Biol Chem. (2000) 275:22905-15. doi: $10.1074 /$ jbc.M001232200

63. Helle KB, Angeletti RH. Chromogranin A: a multipurpose prohormone? Acta Physiol Scand. (1994) 152:1-10.

64. Iacangelo AL, Eiden LE. Chromogranin A: current status as a precursor for bioactive peptides and a granulogenic/sorting factor in the regulated secretory pathway. Regul Pept. (1995) 58:65-88.

65. Mizuno K, Minamino N, Kangawa K, Matsuo H. A new family of endogenous "big" Met-enkephalins from bovine adrenal medulla: purification and structure of docosa- (BAM-22P) and eicosapeptide (BAM-20P) with very potent opiate activity. Biochem Biophys Res Commun. (1980) 97:1283-90.

66. Kitamura K, Kangawa K, Kawamoto M, Ichiki Y, Nakamura S, Matsuo H, et al. Adrenomedullin: a novel hypotensive peptide isolated from human pheochromocytoma. Biochem Biophys Res Commun. (1993) 192:553-60. doi: 10.1006/bbrc. 1993.1451

67. Mahata S.K, Mahata M, Parmer RJ, O'Connor DT. Desensitizaton of catecholamine release. The novel catecholammine release-inhibitory peptide catestatin (chromogranin A344-364) acts at the receptor to prevent nicotinic cholinergic tolerance. J Biol Chem. (1999) 274:2920-8.

68. Sahu BS, Mahata S, Bandyopadhyay K, Mahata M, Avolio E, Pasqua T, et al. Catestatin regulates vesicular quanta through modulation of cholinergic and peptidergic (PACAPergic) stimulation in PC12 cells. Cell Tissue Res. 1-20. doi: 10.1007/s00441-018-2956-1

69. Houchi H, Teraoka K, Oka M, Murakumo Y, Morita K. Substance P inhibits catecholamine biosynthesis stimulated by carbamylcholine in cultured adrenal chromaffin cells. Biochem Pharmacol. (1993) 45:1165-7.

70. Bunn SJ, Marley PD, Livett BG. Receptor stimulated formation of inositol phosphates in cultures of bovine adrenal medullary cells: the effects of bradykinin, bombesin and neurotensin. Neuropeptides (1990) 15:187-94.

71. Livett BG, Kozousek V, Mizobe F, Dean DM. Substance P inhibits nicotinic activation of chromaffin cells. Nature (1979) 278:256-7.

72. Mahapatra NR, O'Connor DT, Vaingankar SM, Hikim AP, Mahata M, Ray S, et al. Hypertension from targeted ablation of chromogranin A can be rescued by the human ortholog. J Clin Invest. (2005) 115:1942-52. doi: $10.1172 /$ JCI24354

73. Kim T, Tao-Cheng JH, Eiden LE, Loh YP. Chromogranin A, an "on/off” switch controlling dense-core secretory granule biogenesis. Cell (2001) 106:499-509. doi: 10.1016/S0092-8674(01)00459-7

74. Montesinos MS, Machado JD, Camacho M, Diaz J, Morales YG, Alvarez de la Rosa D, et al. The crucial role of chromogranins in storage and exocytosis revealed using chromaffin cells from chromogranin A null mouse. J Neurosci. (2008) 28:3350-8. doi: 10.1523/JNEUROSCI.5292-07.2008

75. Tsigelny IF, Kouznetsova VL, Biswas N, Mahata SK, O'Connor DT. Development of a pharmacophore model for the catecholamine releaseinhibitory peptide catestatin: virtual screening and functional testing identify novel small molecule therapeutics of hypertension. Bioorg Med Chem. (2013) 21:5855-69. doi: 10.1016/j.bmc.2013.07.008

76. Stadinski BD, Delong T, Reisdorph N, Reisdorph R, Powell RL, Armstrong $\mathrm{M}$, et al. Chromogranin A is an autoantigen in type 1 diabetes. Nat Immunol. (2010) 11:225-31. doi: 10.1038/ni.1844

77. Kennedy BP, Mahata SK, O'Connor DT, Ziegler MG. Mechanism of cardiovascular actions of the chromogranin A fragment catestatin in vivo. Peptides (1998) 19:1241-8.

78. Helle KB. The chromogranin A-derived peptides vasostatin-I and catestatin as regulatory peptides for cardiovascular functions. Cardiovasc Res. (2009) 85:9-16. doi: $10.1093 / \mathrm{cvr} / \mathrm{cvp} 266$

79. Lembo PM, Grazzini E, Groblewski T, O’Donnell D, Roy MO, Zhang J, et al. Proenkephalin A gene products activate a new family of sensory neuronspecific GPCRs. Nat Neurosci. (2002) 5:201-9. doi: 10.1038/nn815

80. Brown CH, Scott V, Ludwig M, Leng G, Bourque CW. Somatodendritic dynorphin release: orchestrating activity patterns of vasopressin neurons. Biochem Soc Trans. (2007) 35:1236-42. doi: 10.1042/BST03 51236

81. Martin AO, Mathieu MN, Chevillard C, Guérineau NC. Gap junctions mediate electrical signaling and ensuing cytosolic $\mathrm{Ca} 2+$ increases 
between chromaffin cells in adrenal slices: a role in catecholamine release. J Neurosci. (2001) 21:5397-405. doi: 10.1523/JNEUROSCI.21-15-053 97.2001

82. Colomer C, Martin AO, Desarménien MG, Guérineau NC. Gap junction-mediated intercellular communication in the adrenal medulla: an additional ingredient of stimulus-secretion coupling regulation. Biochim Biophys Acta (2011) 1818:1937-51. doi: 10.1016/j.bbamem.2011. 07.034

83. Cena V, Nicolas GP, Sanchez-Garcia P, Kirpekar SM, Garcia AG, Pharmacological dissection of receptor-associated and voltage-sensitive ionic channels involved in catecholamine release. Neuroscience (1983) 10:1455-62.

84. Guerineau NC. Gap junction communication between chromaffin cells: the hidden face of adrenal stimulus-secretion coupling. Pflugers Arch. (2018) 470:89-96. doi: 10.1007/s00424-017-2032-9

85. Colomer C, Olivos Ore LA, Coutry N, Mathieu MN, Arthaud S, Fontanaud P, et al. Functional remodeling of gap junction-mediated electrical communication between adrenal chromaffin cells in stressed rats. J Neurosci. (2008) 28:6616-26. doi: 10.1523/JNEUROSCI.5597-07.2008

86. Desarmenien MG, Jourdan C, Toutain B, Vessières E, Hormuzdi SG, Guérineau NC. Gap junction signalling is a stress-regulated component of adrenal neuroendocrine stimulus-secretion coupling in vivo. Nat Commun. (2013) 4:2938. doi: 10.1038/ncomms3938

87. Farnsworth NL, Benninger RK. New insights into the role of connexins in pancreatic islet function and diabetes. FEBS Lett. (2014) 5881278-87. doi: 10.1016/j.febslet.2014.02.035

88. Goldstein DS, Kopin IJ. Adrenomedullary, adrenocortical, and sympathoneural responses to stressors: a meta-analysis. Endocr Regul. (2008) 42:111-9.

89. Eskay RL, Eiden LE. Interleukin-1 alpha and tumor necrosis factor alpha differentially regulate enkephalin, vasoactive intestinal polypeptide, neurotensin, and substance P biosynthesis in chromaffin cells. Endocrinology (1992) 130:2252-8.

90. Ait-Ali D, Turquier V, Grumolato L, Yon L, Jourdain M, Alexandre D, et al. The proinflammatory cytokines tumor necrosis factor-alpha and interleukin-1 stimulate neuropeptide gene transcription and secretion in adrenochromaffin cells via activation of extracellularly regulated kinase $1 / 2$ and p38 protein kinases, and activator protein-1 transcription factors. Mol. Endocrinol. (2004) 18:1721-39. doi: 10.1210/me.2003-0129

91. Ait-Ali D, Turquier V, Tanguy Y, Thouënnon E, Ghzili H, Mounien L, et al. Tumor necrosis factor (TNF)-alpha persistently activates nuclear factor-kappaB signaling through the type 2 TNF receptor in chromaffin cells: implications for long-term regulation of neuropeptide gene expression in inflammation. Endocrinology (2008) 149:2840-52. doi: 10.1210/en. 2007-1192

92. Douglas SA, Sreenivasan D, Carman FH, Bunn SJ. Cytokine interactions with adrenal medullary chromaffin cells. Cell Mol Neurobiol. (2010) 30:1467-75. doi: 10.1007/s10571-010-9593-x

93. Commoner B. The Closing Circle: Nature, Man And Technology. New York, NY: Penguin Random House (1971).

94. Curras-Freixes M, Piñeiro-Yañez E, Montero-Conde C, ApellánizRuiz M, Calsina B, Mancikova V, et al. PheoSeq: a targeted nextgeneration sequencing assay for pheochromocytoma and paraganglioma diagnostics. J Mol Diagn. (2017) 19:575-88. doi: 10.1016/j.jmoldx.2017. 04.009.

95. Lenders JWM, Eisenhofer G. Update on modern management of pheochromocytoma and paraganglioma. Endocrinol Metab. (2017) 32:152-61. doi: 10.3803/EnM.2017.32.2.152

Conflict of Interest Statement: The authors declare that the research was conducted in the absence of any commercial or financial relationships that could be construed as a potential conflict of interest.

Copyright () 2018 Eiden and Jiang. This is an open-access article distributed under the terms of the Creative Commons Attribution License (CC BY). The use, distribution or reproduction in other forums is permitted, provided the original author(s) and the copyright owner(s) are credited and that the original publication in this journal is cited, in accordance with accepted academic practice. No use, distribution or reproduction is permitted which does not comply with these terms. 